\title{
Different Mechanisms for Loss and Recovery of Binocularity in the Visual Cortex
}

\author{
David S. Liao, ${ }^{1}$ Amanda F. Mower, ${ }^{1,3}$ Rachael L. Neve, ${ }^{4}$ Carmen Sato-Bigbee, ${ }^{2}$ and Ary S. Ramoa ${ }^{1}$ \\ Departments of ${ }^{1}$ Anatomy and Neurobiology and ${ }^{2}$ Biochemistry, and ${ }^{3}$ The Neuroscience Program, Virginia \\ Commonwealth University School of Medicine, Richmond, Virginia 23298-0709, and ${ }^{4}$ Department of Psychiatry, Harvard \\ Medical School, McLean Hospital, Belmont, Massachusetts 02478
}

Diverse molecular mechanisms have been discovered that mediate the loss of responses to the deprived eye during monocular deprivation. cAMP/Ca ${ }^{2+}$ response element-binding protein (CREB) function, in particular, is thought to be essential for ocular dominance plasticity during monocular deprivation. In contrast, we have very little information concerning the molecular mechanisms of recovery from the effects of monocular deprivation, even though this information is highly relevant for understanding cortical plasticity. To test the involvement of CREB activation in recovery of responses to the deprived eye, we used herpes simplex virus (HSV) to express in the primary visual cortex a dominant-negative form of CREB (HSV-mCREB) containing a single point mutation that prevents its activation. This mutant was used to suppress CREB function intracortically during the period when normal vision was restored in two protocols for recovery from monocular deprivation: reverse deprivation and binocular vision. In the reverse deprivation model, inhibition of CREB function prevented loss of responses to the newly deprived eye but did not prevent simultaneous recovery of responses to the previously deprived eye. Full recovery of cortical binocularity after restoration of binocular vision was similarly unaffected by HSV-mCREB treatment. The HSV-mCREB injections produced strong suppression of CREB function in the visual cortex, as ascertained by both DNA binding assays and immunoblot analysis showing a decrease in the expression of the transcription factor $\mathrm{C} / \mathrm{EBP} \beta$, which is regulated by CREB. These results show a mechanistic dichotomy between loss and recovery of neural function in visual cortex; CREB function is essential for loss but not for recovery of deprived eye responses.

Key words: CREB; ocular dominance plasticity; recovery of function; primary visual cortex; monocular deprivation; herpes simplex virus
The monocular deprivation model of amblyopia is one of the most well characterized models of neuronal plasticity. Monocular eyelid suture during a critical period of development leads to a dramatic loss of responses to the deprived eye and to subsequent loss of connections relaying information from this eye (Wiesel and Hubel, 1965). Recovery of binocular function can be obtained, however, if normal visual stimulation to the deprived eye is promptly restored. Understanding the mechanisms of loss and recovery of responses to the deprived eye may have significant implications for understanding cortical plasticity and developing novel therapeutic approaches for amblyopia.

To date, many molecular mediators of the functional loss of connections that occurs during monocular deprivation have been discovered. Recent cDNA array analysis has shown that several clusters of genes may be involved in visual cortical plasticity (Prasad et al., 2002). Some specific molecules include NMDA receptors (Bear et al., 1990; Rauschecker et al., 1990; Roberts et al., 1998), neurotrophins (Maffei et al., 1992; Galuske et al., 2000; Gillespie et al., 2000), and protein kinase A (Beaver et al., 2001). A common mechanism through which these molecules might act in ocular dominance plasticity is phosphorylation of the cAMP/

Received April 29, 2002; revised July 31, 2002; accepted Aug. 6, 2002.

This work was supported by National Eye Institute Grant EY-11508 and National Institute on Alcohol Abuse and Alcoholism Grant AA-13023 (A.S.R.).

Correspondence should be addressed to Dr. Ary S. Ramoa, Department of Anatomy and Neurobiology, Virginia Commonwealth University, School of Medicine, 1101 East Marshall Street, Sanger Hall, Room 12-042, Richmond, VA 232980709. E-mail: aramoa@hsc.vcu.edu.

Copyright @ 02002 Society for Neuroscience $0270-6474 / 02 / 229015-09 \$ 15.00 / 0$
$\mathrm{Ca}^{2+}$ response element-binding protein (CREB), which in turn regulates the transcription of plasticity-related genes (Gonzalez and Montminy, 1989; Deisseroth et al., 1996; Finkbeiner et al., 1997). More recent experiments have indeed shown that CREB function is necessary for the occurrence of an ocular dominance shift during monocular deprivation (Mower et al., 2002).

We have much less information concerning the mechanisms of recovery from the effects of monocular deprivation. Previous experiments have suggested that recovery and loss of function may share the same molecular mediators, specifically NMDA receptors ( $\mathrm{Gu}$ et al., 1989; Bear et al., 1990). An interesting implication of these results is that CREB function may also be necessary for recovery. Consistent with this possibility, upregulation of CREB has been observed in models of cortical recovery from scotoma (Obata et al., 1999). However, evidence exists that challenges the notion of common mechanisms for loss and recovery of visual cortical function. First, although binocular competition is thought to drive the loss of cortical connections mediating responses from the deprived eye, binocular competition cannot drive recovery because initially the deprived eye cannot activate cortical neurons. Second, clinical findings showing that recovery from amblyopia can occur after the critical period for the effects of monocular deprivation (Birnbaum et al., 1977) suggest that different sensitive periods characterize loss and recovery of visual acuity (Daw, 1998). In conclusion, it remains unclear whether the mechanisms that mediate loss of cortical binocular function can also contribute to recovery.

To test the involvement of CREB activation in recovery of 
cortical function after monocular deprivation, we used viral mediated gene transfer of a dominant-negative mutant (mCREB) to suppress cortical CREB function (Carlezon et al., 1998) in the visual cortex of ferrets during the period when normal vision is restored to the deprived eye. Vectors expressing CREB and LacZ were used as controls. This methodology is advantageous in that it allows temporally and spatially restricted expression of transgenes while preserving normal visual cortical responses (Mower et al., 2002). Quantitative in vivo recording techniques were then used to assess recovery. Results show that CREB function is essential for loss, but not recovery, of cortical neuron responses to the deprived eye.

\section{MATERIALS AND METHODS}

Overall experimental design. Ferrets at postnatal day 45 (P45), the peak of ocular dominance plasticity (Issa et al., 1999), had the eyelid of one eye sutured closed to prevent patterned visual stimulation. After 5-7 d of monocular deprivation, ferrets received two intracortical injections of herpes simplex virus (HSV) vectors expressing CREB, mCREB, or LacZ (HSV-CREB, HSV-mCREB, and HSV-LacZ, respectively). In some injections, mCREB was tagged with green fluorescent protein (HSVmCREB-GFP). One day after the injections, one group of ferrets (reverse deprivation group) had the eyelid of the deprived eye opened and the lid of the experienced eye sutured closed, while another group (binocular recovery group) had their eyelids opened to restore binocular vision. The reverse deprivation and binocular vision were started $1 \mathrm{~d}$ after injection to make certain of adequate transgene expression before recovery. The length of reverse deprivation or binocular vision after monocular deprivation was chosen to ensure maximal transgene expression during the recovery period (Carlezon et al., 1998) as well as full recovery of deprived eye responses in the untreated cortex (see Results). After $3 \mathrm{~d}$ of reverse deprivation or binocular vision, the animals were anesthetized, and quantitative single-unit electrophysiology was performed to assess changes in cortical ocular dominance. The injections led to patches of infected cells $\sim 1 \mathrm{~mm}$ in diameter; areas of uninfected cells lateral and medial to the infected cells within the same hemisphere were used for control recordings. The Institutional Animal Care and Use Committee of Virginia Commonwealth University approved all procedures described here.

Injection of viruses. Animals were premedicated by subcutaneous injection of a tranquilizer (acepromazine, $1 \mathrm{mg} / \mathrm{kg}$ ) and a muscarinic antagonist (methyl atropine bromide, $0.2 \mathrm{mg} / \mathrm{kg}$ ) to reduce bronchial secretions, anesthetized with intraperitoneal sodium pentobarbital (35 $\mathrm{mg} / \mathrm{kg}$ ), and placed in a stereotaxic frame. No surgical procedures were initiated until animals were sufficiently anesthetized, as ascertained by the loss of withdrawal and corneal-blink reflexes. A small craniotomy $(\sim 1$ $\mathrm{mm}$ diameter) was performed above the binocular region of the primary visual cortex. Next, the tip of a 32 gauge Hamilton syringe (Hamilton Company, Reno, NV) containing the virus (average titer of the purified virus stocks, $4.0 \times 10^{7}$ infectious units $/ \mathrm{ml}$ ) was lowered stereotaxically through the dura mater and into the binocular region of the primary visual cortex to a depth of $1 \mathrm{~mm}$. A volume of $2.0 \mu \mathrm{l}$ was injected at a rate of $0.2 \mu \mathrm{l} / \mathrm{min}$. We have shown previously that these injections result in robust transgene expression in a restricted area of cortex, leaving a large uninfected region available for control recordings in the same hemisphere (Mower et al., 2002).

Extracellular recordings in vivo. Animals were premedicated by subcutaneous injection of acepromazine $(1 \mathrm{mg} / \mathrm{kg})$ and methyl atropine bromide $(0.2 \mathrm{mg} / \mathrm{kg})$, anesthetized with intraperitoneal sodium pentobarbital $(35 \mathrm{mg} / \mathrm{kg})$, and placed in a stereotaxic frame. No surgical procedures were initiated until the animals were sufficiently anesthetized, as ascertained by the loss of withdrawal and cornea-blink reflexes. Surgery consisted of a craniotomy (3-5 $\mathrm{mm}$ in diameter) over the binocular region of the primary visual cortex within which recordings were conducted. A tracheal cannulation was performed, and the animal was placed on a ventilator. Expired $\mathrm{pCO}_{2}$ and $\mathrm{SpO}_{2}$ were monitored continuously and maintained at $\sim 4.0 \%$ and above $90 \%$, respectively. Body temperature was maintained at $38^{\circ} \mathrm{C}$ using a homeostatic blanket. Withdrawal reflexes and heart rate were monitored during the experiment. Supplemental doses of pentobarbital and acepromazine were given along with subcutaneous injections of $10 \%$ dextrose and $0.9 \%$ saline every hour throughout the experiment or when heart rate or expired $\mathrm{pCO}_{2}$ in- creased. The eyelids were opened, nictitating membranes were retracted using pseudoephedrine $(2.5 \%)$, the pupils were dilated with atropine sulfate $(1 \%)$, and contact lenses were placed on the corneas

A tungsten-in-glass electrode (Levick, 1972) was used to make singleunit recordings from both the treated and untreated portions of the hemisphere contralateral to the deprived eye (first deprived eye in the case of the reverse deprivation group). Recordings of treated cells were made in electrode penetrations within $500 \mu \mathrm{m}$ of the injection site, whereas control recordings were made at least $2 \mathrm{~mm}$ away. Histological examination confirmed that the recordings of treated cells were made within the area of infection, whereas control recordings were outside of this region. Once a single unit was isolated, its receptive field, ocular dominance, preferred orientation, direction, and velocity were qualitatively determined using a moving bar of light $0.5^{\circ}$ wide and $20^{\circ}$ long. Ocular dominance was then quantitatively determined by presenting a computer-controlled light bar stimulus to each eye 10 times. Each stimulus presentation consisted of the bar of light moving across the receptive field first in one direction and then in the opposite direction. Evoked responses and spontaneous activity were recorded using Spike2 software (Cambridge Electronics Design, Cambridge, UK). Spontaneous activity was determined by recording in the absence of stimulation for at least 2 $\mathrm{sec}$ after each presentation. Electrolytic lesions $(4 \mu \mathrm{A}$ for $5 \mathrm{sec})$ were made at the end of each penetration. After the conclusion of the experiment, the animal was killed with Euthansol ( $125 \mathrm{mg} / \mathrm{kg}$ pentobarbital). When the expired $\mathrm{pCO}_{2}$ began to fall, the animal was perfused transcardially with $0.9 \%$ saline followed by $4 \%$ paraformaldehyde. The brain was postfixed for at least $12 \mathrm{hr}$, after which the primary visual cortex was cut into $50 \mu \mathrm{m}$ sections in the coronal plane using a vibratome. Alternating sections were stained with cresyl violet and the appropriate antibody. Cresyl violet staining was used to reconstruct electrode recording tracts, and immunohistochemistry was used to confirm expression of the transgenes within the primary visual cortex.

Quantification of ocular dominance. Using peristimulus histograms generated for each cell in Spike2, the number of spikes evoked for each eye was determined by measuring the total neuronal response during stimulus presentation. The spontaneous activity was then subtracted from the total number of spikes. To quantify cortical binocularity, an ocular dominance index was then calculated for each cell as described in Results. To analyze the results statistically, we calculated a contralateral bias index $(\mathrm{CBI})$ defined as $\left[\left(P_{0.00-0.19}-P_{0.80-1.00}\right)+\left(P_{0.20-0.39}-\right.\right.$ $\left.P_{0.40-0.69} / 2+100\right] / 200$, where $P_{A-B}$ denotes the percentage of cells with binocular indices between $A$ and $B$. We obtained for each animal a CBI for recordings performed in treated cortex and a CBI for recordings performed in untreated control cortex in the same hemisphere. A Wilcoxon Mann-Whitney $U$ test was then used to determine for each experimental group whether CBIs obtained in the treated and untreated regions were significantly different from each other.

Immunohistochemistry. Free-floating sections were washed three times for 10 min each in $0.1 \mathrm{M}$ PBS with $0.3 \%$ Triton X-100 (Sigma, St. Louis, MO). Endogenous peroxidase activity was quenched by a 20 min incubation with $1 \% \mathrm{H}_{2} \mathrm{O}_{2}$ in PBS with $0.3 \%$ Triton $\mathrm{X}-100$. The sections were again washed as above and were blocked for $1 \mathrm{hr}$ with $0.3 \%$ Triton $\mathrm{X}-100-10 \%$ normal goat serum-2\% bovine serum albumin in PBS. Sections were then incubated overnight at $4^{\circ} \mathrm{C}$ with rabbit anti-CREB IgG (1:1000; Upstate Biotechnology, Lake Placid, NY) in blocking solution. The sections were again washed as above and were incubated with biotinylated goat anti-rabbit IgG (1:1000; Vector Laboratories, Burlingame, CA). After another wash, sections were incubated with ABC solution (Vectastain Elite ABC kit; Vector Laboratories) for $1 \mathrm{hr}$. After a final wash, sections were reacted with $0.06 \%$ cobalt enhanced 3,3'diaminobenzidine tetrahydrochloride (Sigma). Sections were mounted on chrom-alum subbed slides, dehydrated through graded alcohols (50, 70, 95, and 100\% ethanol) and clearing agent (Stephens Scientific, Riverdale, NJ), and mounted in Permount (Fisher Scientific, Fair Lawn, $\mathrm{NJ})$. For visualization of $L a c Z$ expression, sections were treated using a $\beta$-Gal Staining Set (Roche Diagnostics Corporation, Indianapolis, IN).

$C R E$ binding assays. mCREB contains a mutation that prevents its phosphorylation at serine 133 without affecting its binding to DNA. To confirm that mCREB expressed by HSV-mCREB competes with endogenous phosphorylated CREB for binding to the cAMP response element (CRE), we performed protein-DNA binding assays in which nuclear extracts from untreated, HSV-mCREB-injected, and HSV-LacZinjected cortices were incubated with oligonucleotides containing the CRE sequence. Cortices were harvested from reverse sutured animals $2 \mathrm{~d}$ after injection of the different HSV vectors, and nuclear extracts were 

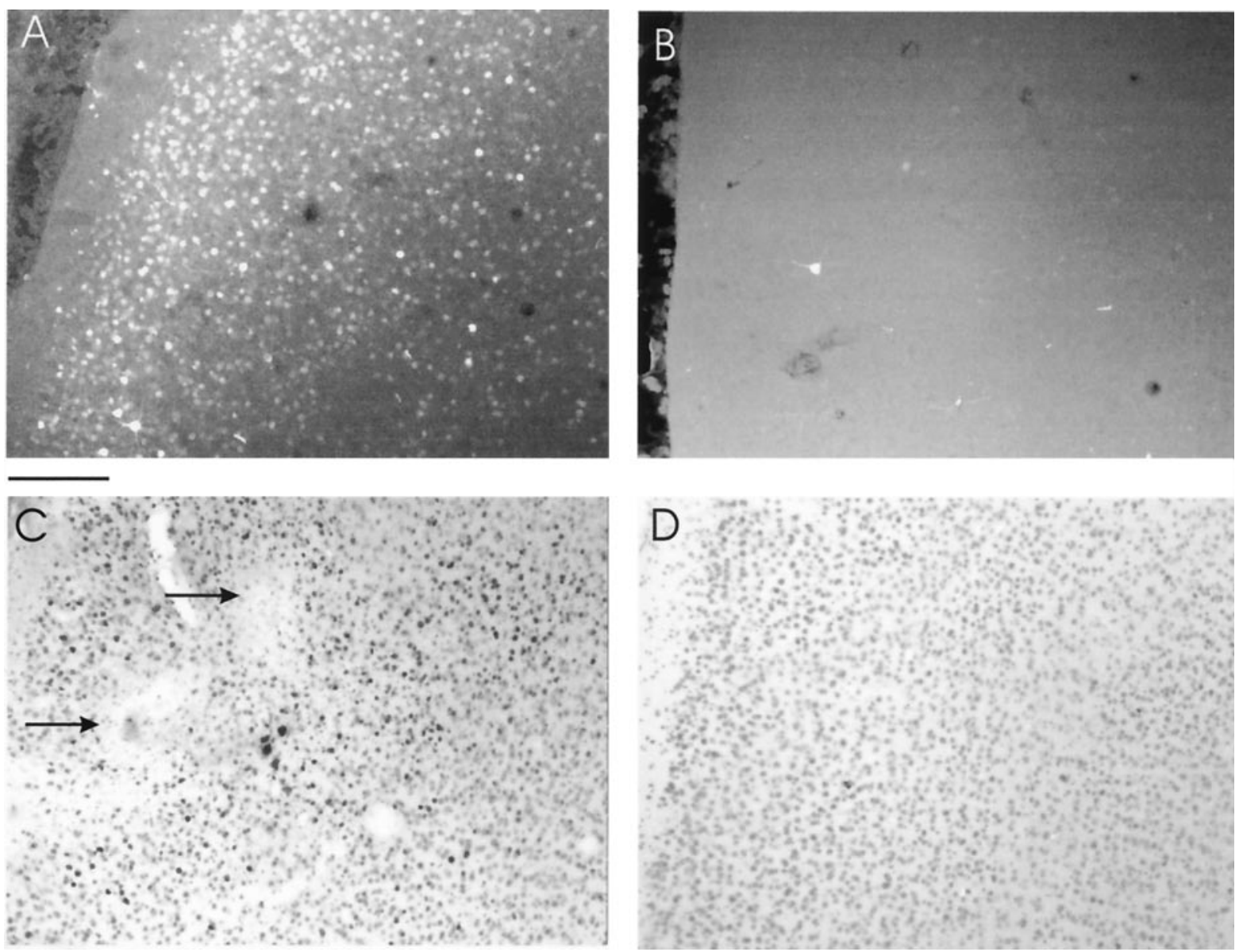

Figure 1. Histological examination shows successful expression of transgenes in the primary visual cortex. $A$, The photomicrograph shows a very large number of cells expressing mCREB-GFP near the site of an injection made $4 \mathrm{~d}$ earlier. Scale bar, $180 \mu \mathrm{m}$. $B$, Few cells expressed mCREB-GFP $\sim 2$ $\mathrm{mm}$ away from the injection. $C$, Darkly labeled cells stained with CREB-specific antibodies (1:1000; Upstate Biotechnology) are seen near the injection of HSV-CREB. Note the presence of electrolytic lesions (arrows) made during an electrode penetration near the injection site. D, Lightly stained cells $\sim 2 \mathrm{~mm}$ away from the injection of HSV-CREB. The immunohistochemical procedures were chosen to minimize detection of endogenous CREB and therefore underestimate the number of infected cells.

prepared according to the methods of Schreiber et al. (1989), with minor adaptations. The tissue was homogenized in a hypotonic buffer (in mM: 10 HEPES, pH 7.9, $10 \mathrm{KCl}, 0.1$ EDTA, 1 DTT, and 0.5 PMSF) and incubated on ice for $20 \mathrm{~min}$ in the presence of protease inhibitors (1:100; Genotech, St. Louis, MO) and phosphatase inhibitors (1:100; Sigma). $10 \%$ NP-40 (1:50; Sigma) was then added, and the cells were vortexed vigorously. The nuclear pellet was collected by centrifugation of the homogenate at $10,000 \times g$ for $30 \mathrm{sec}$ at $4^{\circ} \mathrm{C}$. The pellet was resuspended in a high-salt buffer B (20 mm HEPES, $\mathrm{pH}$ 7.9, $0.4 \mathrm{M} \mathrm{NaCl}, 1 \mathrm{~mm}$ EDTA, $1 \mathrm{mM}$ DTT, and $1 \mathrm{~mm}$ PMSF) to dissociate proteins bound to the DNA and incubated on ice for $15 \mathrm{~min}$. The extract was centrifuged at $11,000 \times$ $g$ for $5 \mathrm{~min}$ at $4^{\circ} \mathrm{C}$. The supernatant containing the nuclear proteins was collected and concentrated using a microconcentrator (Centricon). During the concentration, buffer B was exchanged for binding buffer $(20 \mathrm{~mm}$ HEPES, 20\% glycerol, $100 \mathrm{~mm} \mathrm{KCl,} 0.2 \mathrm{~mm}$ EDTA, $0.2 \mathrm{~mm}$ DTT, 1:100 protease inhibitors). The $5^{\prime}$ biotinylated oligonucleotide containing the CRE (5'GATCAGAGATTGCCTGACGTCAGAGAGCTAG-3') and its complement (Ransom Hill Bioscience, Ramona, CA) were annealed and incubated with streptavidin-coated agarose beads (Upstate Biotechnology). The bead-oligonucleotide complex was incubated with the nuclear extract (at least $30 \mu \mathrm{g}$ of protein per $50 \mu \mathrm{l}$ of beads) in the presence of $1 \mu \mathrm{g} / \mathrm{ml}$ poly(dI-dC) for $2 \mathrm{hr}$ at room temperature. After the binding reaction, the nuclear extract/bead suspension was centrifuged at $10,000 \times g$ for $3 \mathrm{~min}$ at $4^{\circ} \mathrm{C}$. The pellet was carefully washed and subjected to SDS-PAGE followed by immunoblot analysis with antiCREB (1:1000; Cell Signaling Technology, Beverly, MA) and antiphospho-CREB (1:500; Upstate Biotechnology) antibodies. To detect $\mathrm{C} / \mathrm{EBP} \beta$, protein assays were performed (Bio-Rad, Hercules, CA), and equal amounts of nuclear protein extract from each treatment group were subjected directly to SDS-PAGE and immunoblot analysis with anti-CEBP $\beta$ (1:500; Santa Cruz Biotechnology, Santa Cruz, CA). Immunoreactive bands were detected by chemiluminescence using SuperSignal West Dura Extended Duration Substrate (Pierce, Rockford, IL). The relative intensities of the bands were determined by scanning densitometric analysis of the $\mathrm{x}$-ray films.

\section{RESULTS}

\section{Cortical expression of transgenes}

Ferrets received intracortical injections of HSV vectors expressing wild-type CREB, mCREB, mCREB tagged with green fluorescent protein (mCREB-GFP), or $\beta$-galactosidase. Intracortical injections of HSV vectors resulted in successful expression of the appropriate transgenes in cells located near the injection site, as shown in Figure 1. Animals injected with HSV-mCREB-GFP exhibited fluorescence in a large number of cells surrounding the injection site (Fig. 1A). In contrast, cells located $\sim 2 \mathrm{~mm}$ away from the injection site were not labeled (Fig. $1 B$ ). Immunohistochemistry using a CREB-specific antibody in animals injected with HSV-CREB (Fig. 1C) or HSV-mCREB (data not shown) showed a large number of darkly labeled cells surrounding electrolytic lesions (Fig. 1C, arrows) that were made at the end of the penetrations. Immunohistochemistry lightly stained endogenous CREB in cells located $\sim 2 \mathrm{~mm}$ away from the injection site (Fig. 


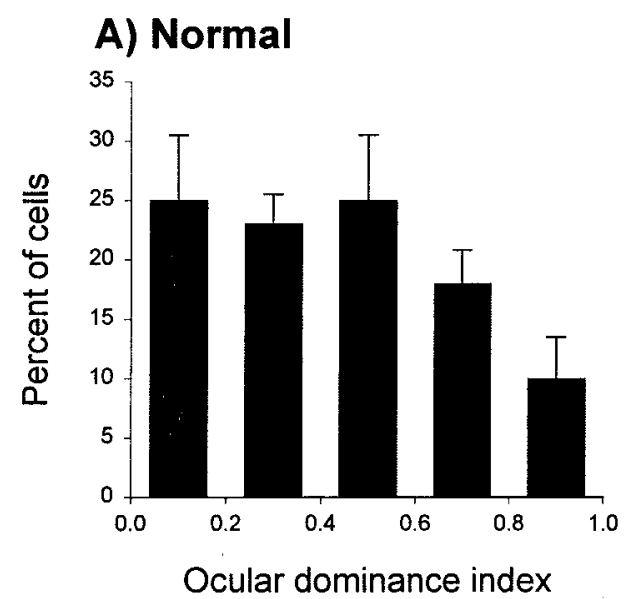

Figure 2. Recovery of responses to the deprived eye in two recovery protocols. Whereas the normal ferret ocular dominance profile is characterized by a high degree of binocularity ( $A ; n=119$ neurons), $\sim 1$ week of monocular lid suture starting at P45 caused a dramatic loss of responses to the deprived eye $(B ; n=110)$. Full recovery of cortical binocularity was present after a $3-5$ d period of binocular vision $(C ; n=$ 228). In contrast, the ocular dominance distribution was shifted back toward the previously deprived eye after a period of reverse deprivation $(D ; n=119)$. In this case, $3 \mathrm{~d}$ of reverse deprivation caused a striking loss of responses to the newly deprived eye and did not induce binocular recovery.
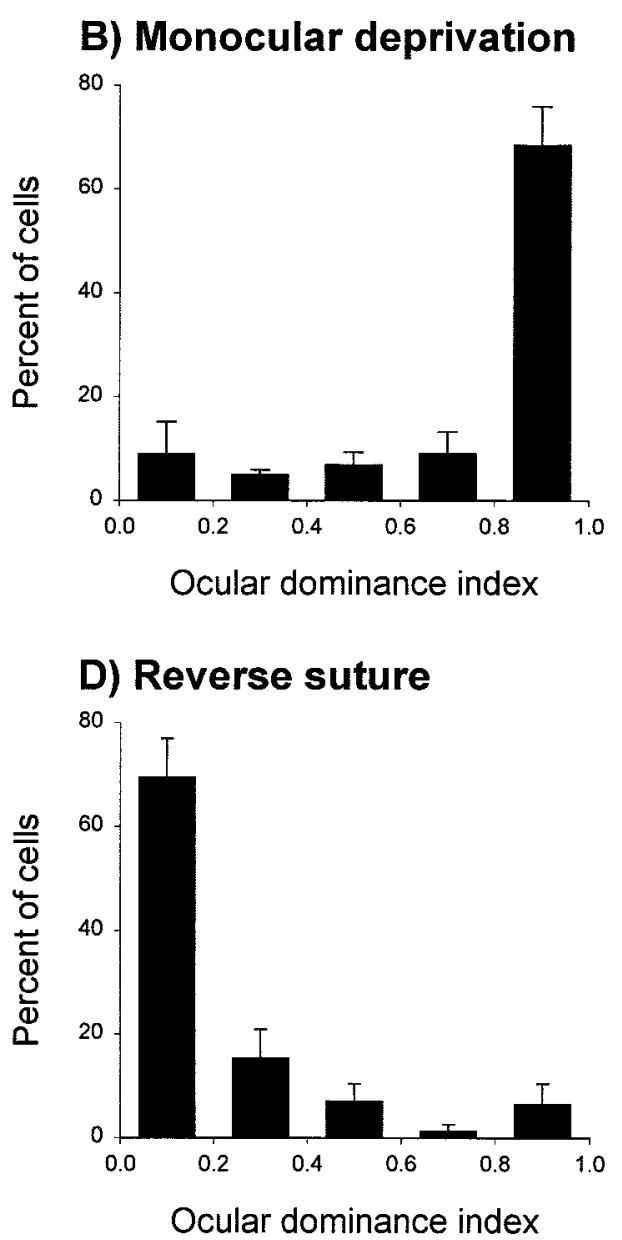

$1 D)$. The conditions used for immunohistochemistry were chosen to minimize the detection of endogenous CREB; therefore, the number of darkly stained cells probably underestimates transgene expression. We only used animals that had at least one successful penetration in each of the control and treated regions of the same hemisphere. Together, these results confirm previous findings showing that successful expression of CREB and control transgenes occurs after intracortical injections of HSV (Mower et al., 2002).

\section{Models of recovery from monocular deprivation}

Ferrets were monocularly deprived for 5-7 d, after which visual input was re-established to the deprived eye in one of two recovery protocols: (1) the eyelid of the deprived eye was opened, and the lid of the experienced eye was sutured closed (reverse deprivation), or (2) the eyelid of the deprived eye was opened to restore binocular vision. Three days after the initiation of recovery, extracellular recordings were conducted in the binocular region of the visual field. To quantify ocular dominance of cortical neurons, we calculated an ocular dominance index using the equation $\mathrm{LE} /(\mathrm{RE}+\mathrm{LE})$, where $\mathrm{LE}$ and RE stands for the response to stimulation of the left and right eye, respectively. An ocular dominance index of 1.0 indicates responsiveness only to the left eye; an index of 0.0 indicates responsiveness only to the right eye.

The effects of the two recovery protocols, binocular vision and reverse deprivation, following a period of monocular deprivation are shown in Figure 2. These histograms show the marked ocular dominance shift relative to normal (compare $A, B$ ) typically seen in ferrets after a period of 5-7 d of monocular deprivation. The ocular dominance distribution shifted back toward the previously deprived eye after $3 \mathrm{~d}$ of reverse deprivation (D). In these animals, the previously deprived eye dominated most cortical responses, and cortical binocularity did not recover. In contrast, a few days of binocular vision after a period of monocular deprivation restored cortical binocularity to the level present before deprivation so that the ocular dominance profile was similar to normal (compare $A, C$ ). In conclusion, these patterns of ocular dominance provide us with two distinctive models of recovery from monocular deprivation: the reverse deprivation model, in which both recovery (to the previously deprived eye) and loss of responses (to the newly deprived eye) are evident, and the binocular recovery model, in which binocular recovery predominates.

\section{Suppression of CREB function during reverse deprivation}

To elucidate the role of CREB function on loss and recovery of responses in the same preparation, we examined the effects of expression of different transgenes on ocular dominance plasticity during reverse deprivation. Specifically, we asked whether CREB function is required in recovery of responses to the previously deprived eye as well as loss of responses to the newly deprived eye. The histograms showing the distribution of neurons into binocularity ranges are shown in Figure 3 for animals that received intracortical injection of $\operatorname{HSV}-\operatorname{mCREB}(A, B)$ and were reverse sutured. As expected, the ocular dominance distribution was markedly shifted toward the previously deprived eye in un- 

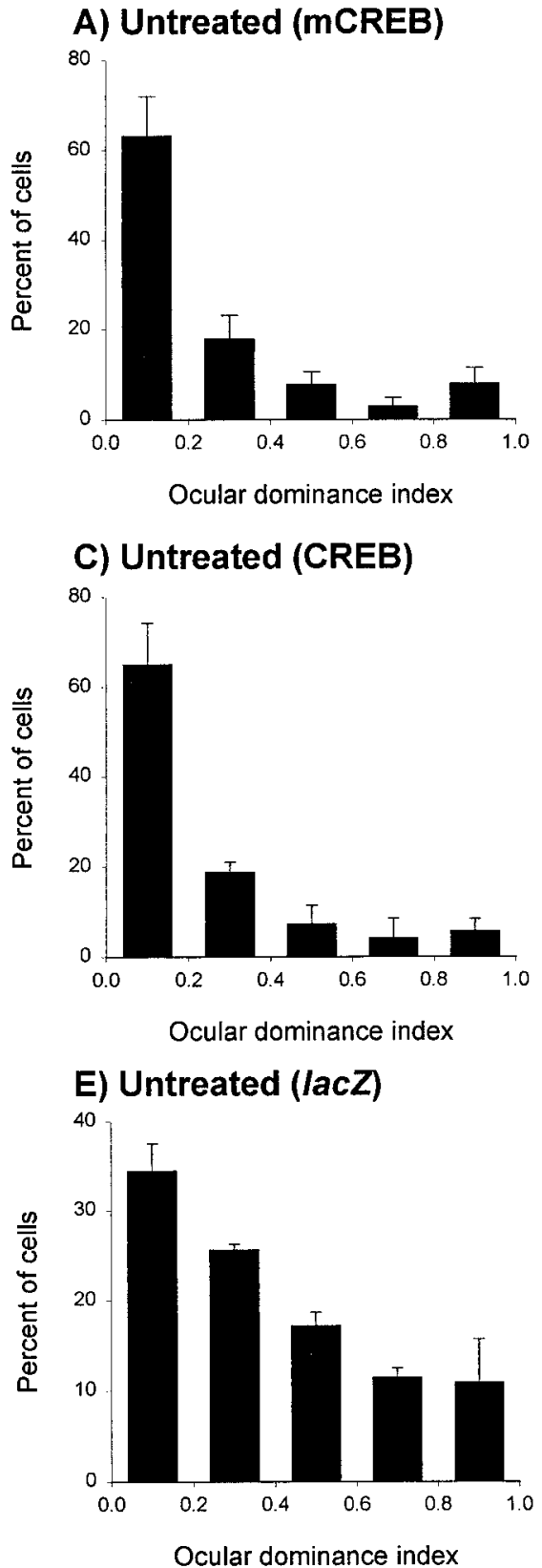
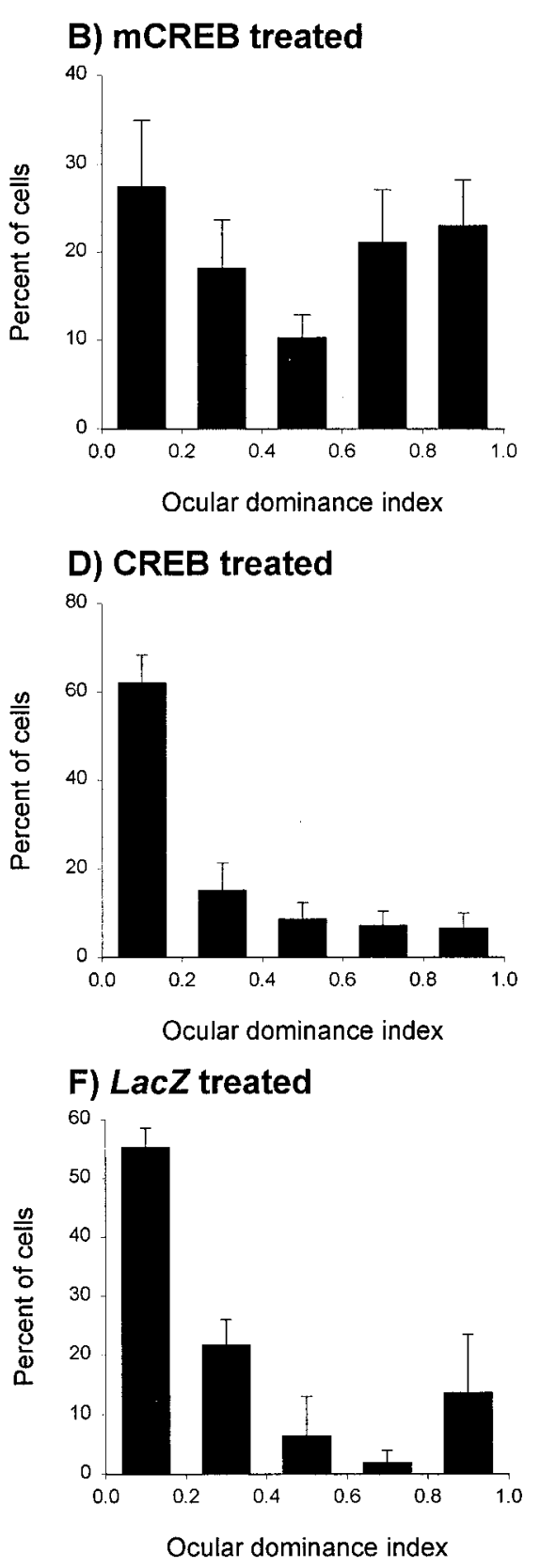

Figure 3. Dichotomy in CREB dependence of recovery and loss of neuronal responses during reverse deprivation. $A, B$, The histograms with error bars show that most neurons located away from the HSV-mCREB-treated cortex $(A)$ responded preferentially to the previously deprived eye. In contrast, recordings in treated cortex revealed that a large proportion of neurons continued to respond to the newly deprived eye $(B)$. However, treatment did not prevent the recovery of responses to the previously deprived eye. Most (84\% of 119) untreated neurons studied in six animals had a binocularity index $<0.5$ after $3 \mathrm{~d}$ of reverse deprivation, indicating that they responded preferentially to the previously deprived eye. In contrast, recordings from 76 neurons located in the treated region of the hemispheres in the same animals indicated that an approximately equal number of cells responded preferentially to stimulation of the previously deprived $(n=42)$ and newly deprived $(n=34)$ eye. Note that several cells are binocularly driven. The results obtained from recordings located near and away from the injection site were significantly different $(p<$ 0.05; Wilcoxon Mann-Whitney $U$ test). $C, D$, The histograms show an ocular dominance shift toward the previously deprived eye in animals treated with HSV-CREB within $3 \mathrm{~d}$. The results obtained from neurons studied near $(C ; n=83$ cells in four animals) and away ( $D ; n=68$ cells) from the injection of HSV-CREB were indistinguishable $(p>0.05)$. $E, F$, Similarly, results obtained from recordings located near ( $E ; n=40$ cells in two animals) and away ( $F ; n=35$ cells) from the injection of HSVlac $Z$ revealed an ocular dominance shift toward the previously deprived eye within $3 \mathrm{~d}$. treated neurons (Fig. 3A). This distribution reflects recovery of responses to the previously deprived eye as well as an almost complete loss of responses to the newly deprived eye. The results observed in penetrations made in untreated cortex located medially and laterally from the injection site were similar and have been pooled together. In contrast to these findings, the ocular dominance shift was markedly reduced in cells recorded within the area of HSV-mCREB infection (Fig. 3B). In these penetrations, a large number of neurons continued to respond preferentially to the newly deprived eye, and several neurons located in the area of infection were binocularly driven. The ocular dominance indices in the group of neurons near the injection site differed significantly from those observed in the group of untreated neurons ( $p<0.05$; Wilcoxon Mann-Whitney $U$ test).

Specificity of these effects was confirmed by examining cortical binocularity in animals treated with intracortical injection of HSV containing the cDNA for CREB (Fig. $3 C, D$ ) or the $L a c Z$ reporter gene (Fig. 3E,F) during reverse deprivation. The regions of untreated and HSV-CREB infected cortex showed similar ocular dominance distributions that were characterized by a pronounced shift toward the previously deprived eye (Fig. $3 C$, D, respectively). The binocularity indices observed in the treated and untreated groups of neurons were not significantly different $(p>$ $0.05)$. Similar results were observed in animals treated with HSVLacZ (Fig. 3E,F). These findings indicate that overexpression of the wild-type protein CREB or expression of the foreign protein $\beta$-galactosidase does not lead to loss of ocular dominance plasticity during reverse deprivation, indicating specificity of the effects observed with HSV-mCREB injection.

\section{Suppression of CREB function during binocular recovery}

The above results suggest that a dichotomy exists between the CREB dependence of recovery and loss of cortical responses. To 


\section{A) Recovery, untreated}

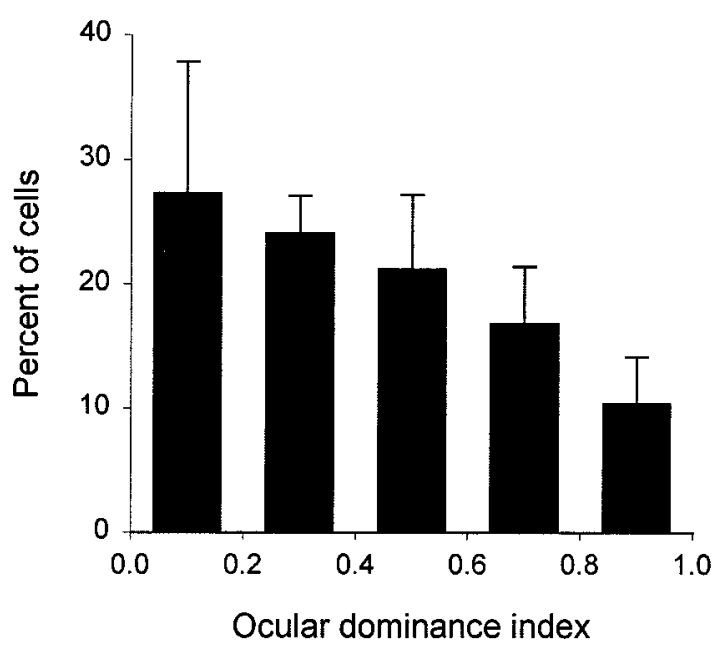

B) Recovery, HSV-mCREB treated

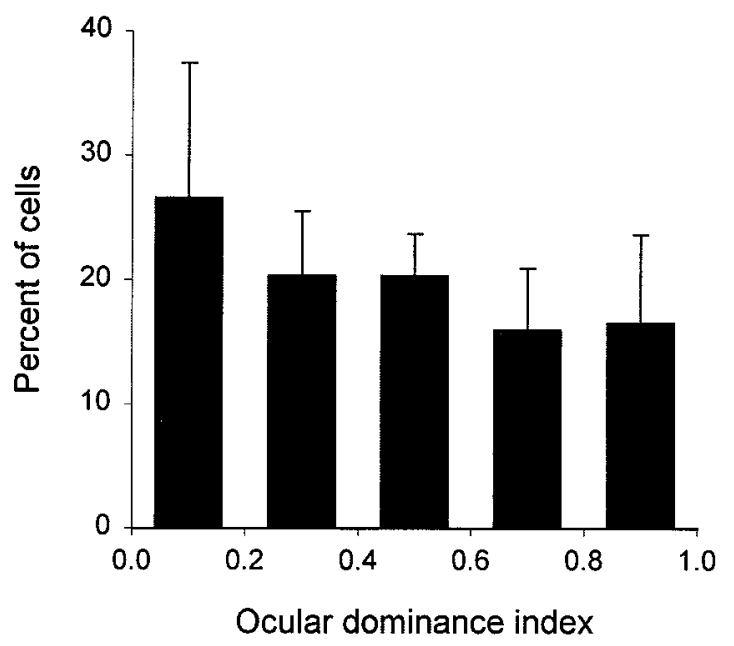

Figure 4. Intracortical injection of HSV-mCREB did not prevent recovery of cortical binocularity during binocular vision. Histograms with error bars show that most neurons located near $(B)$ as well as away $(A)$ from the HSV-mCREB-treated cortex fully recovered cortical binocularity relative to normal animals (compare with Fig. $2 A$ ). The results obtained from recordings located near ( $n=93$ cells in 5 animals) and away $(n=92$ cells in the same hemispheres as the treated cells) were statistically indistinguishable $(p>0.05)$.

test this idea further, we suppressed CREB function in the binocular recovery group of animals, in which recovery predominates. Similar ocular dominance profiles were observed in untreated (Fig. 4A) and treated (Fig. 4B) cortices, showing that injection of HSV-mCREB did not prevent recovery of cortical binocularity. The binocularity indices observed in the treated and untreated groups of neurons were not different $(p>0.05)$. Thus, suppression of CREB function at the time when binocular vision is restored does not prevent recovery of responses to the previously deprived eye. Together, the results from the reverse deprivation and binocular recovery animals indicate that CREB function is required in loss, but not recovery of functional connections after a brief period of monocular deprivation.

\section{Suppression of CREB function by HSV-mCREB injections}

To examine whether lack of effects of HSV-mCREB injection on recovery of responses to the deprived eye resulted from inappropriate blockade of CREB function, we conducted two assays to verify transgene activity in visual cortex. We performed DNA binding assays using nuclear extracts obtained from untreated, HSV-mCREB-treated, and HSV-LacZ-treated cortices of animals subjected to reverse deprivation. These studies predict that if mCREB expression is to successfully block endogenous CREB activity, it must compete with CREB for CRE binding sites. Therefore, the presence of CRE-bound MCREB should decrease the amount of CRE-bound endogenous CREB, thereby downregulating CRE-mediated gene transcription. Because mCREB is unphosphorylatable, the ratio of CRE-bound phospho-CREB to total CREB (CREB plus mCREB) should also decrease. To examine these possibilities, we have incubated nuclear extracts from untreated, HSV-mCREB-treated, and HSV-LacZ-treated hemispheres with a double-stranded oligonucleotide containing the CRE sequence (see Materials and Methods). The relative proportion of phospho- to total CREB bound to the oligonucleotide was detected by Western blot analysis (Fig. 5A,B). These experiments show that the ratio of CRE-bound phospho-CREB to CRE-bound total CREB is markedly lower in HSV-mCREBtreated than in normal or HSV-LacZ-treated cortices, indicating that mCREB competes efficiently with endogenous CREB for binding to CRE elements.

To confirm whether this competition results in decreased expression of genes that are transcriptionally regulated by CREB, we have examined the expression of the transcription factor $\mathrm{C} / \mathrm{EBP} \beta$ (Niehof et al., 1997) in animals that were reverse deprived. Effects of HSV injections on protein expression were examined and quantified using specific antibodies in Western blotting. The results shown in Figure 6 indicate that $\mathrm{C} / \mathrm{EBP} \beta$ expression was downregulated in nuclear extracts from HSVmCREB-injected cortex relative to HSV-LacZ-injected cortex. In conclusion, the findings that expression of mCREB efficiently decreased the binding of phospho-CREB to the CRE and successfully suppressed expression of a CREB-regulated gene further substantiate the evidence that a dichotomy exists in CREB dependence of the processes of recovery and loss of neural function in visual cortex.

\section{DISCUSSION}

\section{Different mechanisms for loss and recovery of deprived eye responses}

The present report makes two major points concerning the mechanisms of cortical recovery from the effects of monocular deprivation. The first point is that suppression of CREB function in the primary visual cortex prevents loss of responses to the newly deprived eye in the reverse suture model of recovery. This finding extends recent results showing that suppression of CREB function in primary visual cortex prevents the loss of responses to the deprived eye during monocular deprivation (Mower et al., 2002). The effect on loss of response was specific and did not result from viral toxicity, because HSV-CREB and HSV-LacZ injections failed to block this type of ocular dominance plasticity. Additionally, the effects did not result from a suppression of sensory responses, because most neurons studied in infected cortex responded strongly to visual stimulation and had stimulus specificities characteristic of the primary visual cortex of ferrets (Mower et al., 2002). These findings indicate that CREB function is 


\section{$\begin{array}{ll}\text { A) Total CREB } & \text { B) phospho-CREB }\end{array}$}

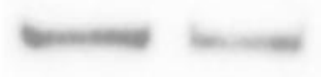

\section{m-CREB LacZ \\ treated treated}

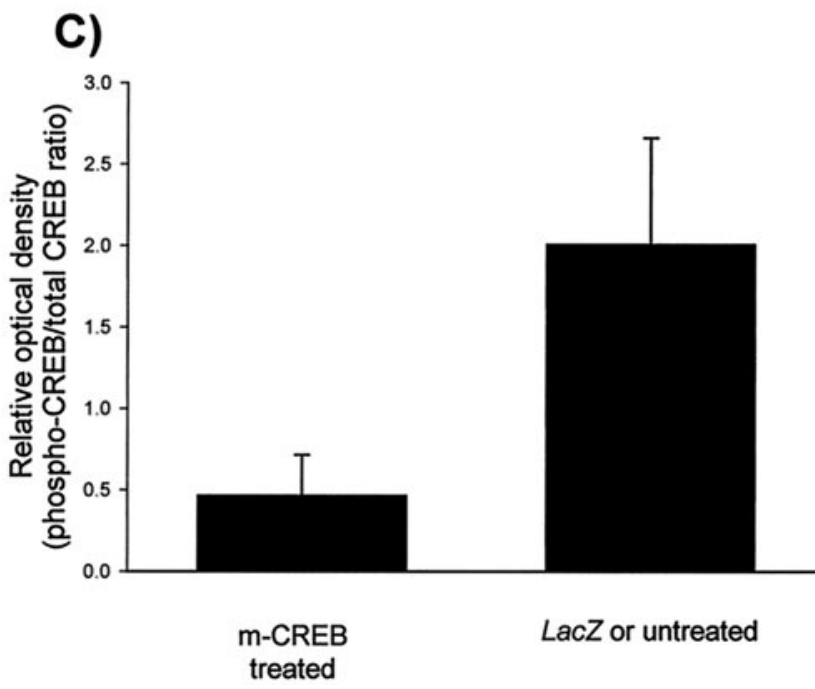

Figure 5. mCREB competes efficiently with endogenous CREB for binding to the CRE. Pairs of nuclear extracts were prepared from cortices of animals $(n=5)$ that received injections of HSV-mCREB in one hemisphere and HSV-LacZ $(n=4)$ or no injection $(n=1)$ in the other. These animals represent a group separate from those used in physiology and histology. In each nuclear extract, the proportion of nonphosphorylated CREB competing with phospho-CREB for binding to the CRE was assessed by using synthetic nucleotides, as described in Materials and Methods. For each sample, the proportion of phospho-CREB to total CREB (phosphorylated + non-phosphorylated) was determined by Western blot analysis after separation of the protein-DNA complexes. $A$, Total CREB; $B$, phospho-CREB. The ratio of $\mathrm{pCREB} /$ total CREB determined after densitometric analysis of the Western blots for mCREB- and LacZtreated samples is represented in $C$. The results from cortices that received HSV-LacZ or no injection were similar and have been pooled. The ratio of phospho- to total CREB bound to the CRE was significantly less in HSV-mCREB-treated animals ( $p<0.05$; paired $t$ test) indicating that mCREB competes for CRE binding sites.

essential for loss of response to the newly deprived eye during reverse deprivation. In the same animals, recovery of responses to the previously deprived eye was not prevented by the HSVmCREB injections, suggesting that CREB function is not required for the recovery of responses to the deprived eye.

The second major point of this study is that suppression of CREB function does not prevent binocular recovery. Full recovery of responses to the deprived eye was observed in regions of

\section{A) $\mathrm{C} / \mathrm{EBP} \beta$}

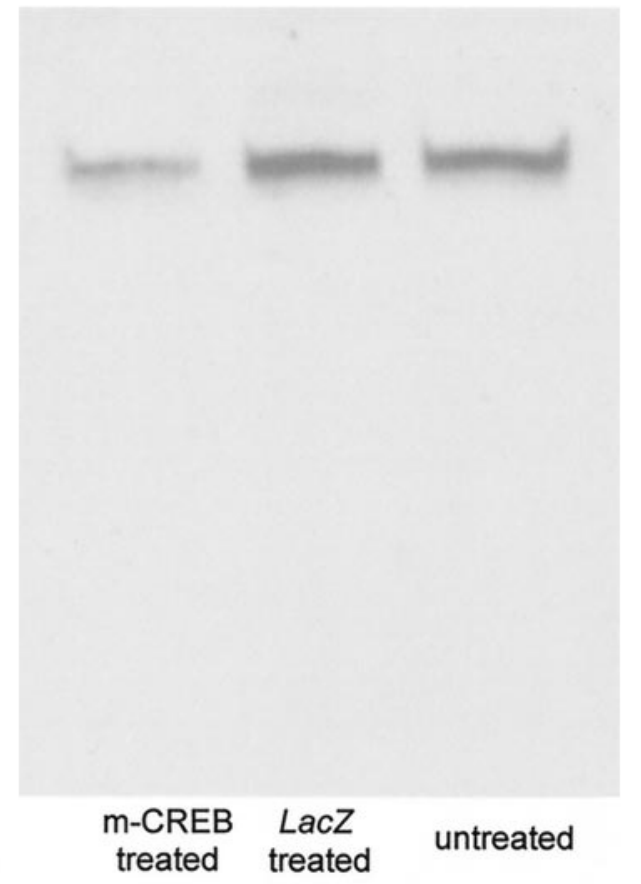

B)

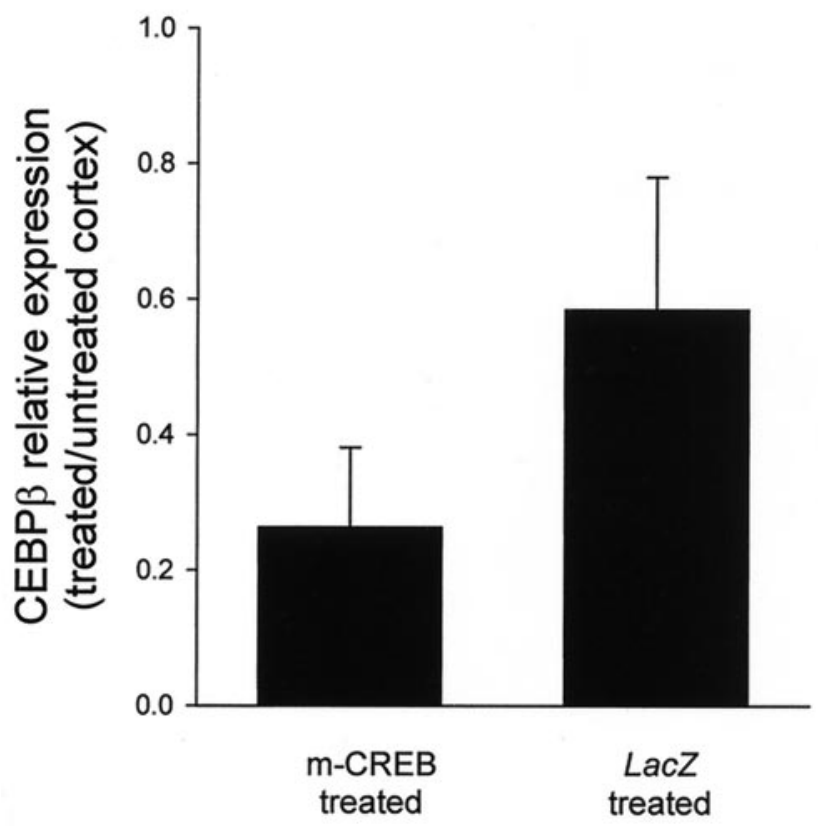

Figure 6. Intracortical injections of HSV-mCREB suppressed expression of $\mathrm{C} / \mathrm{EBP} \beta$. C/EBP $\beta$ expression in samples prepared from animals $(n=4)$ receiving HSV-mCREB injections in one hemisphere and HSV$L a c Z$ in the other was determined by Western blot analysis. These animals were separate from those used for physiology. For each blot, equal amounts of protein were loaded in each lane. The immunoblots show that $\mathrm{C} / \mathrm{EBP} \beta$ expression in visual cortex near the site of HSV$\mathrm{mCREB}$ treatment is reduced relative to HSV-LacZ-treated cortex $(A)$. The bar graphs show that average optical densities for cortex treated with HSV-mCREB are significantly less than those treated with HSV-LacZ when normalized to untreated cortex from the same animals $(p \leq 0.05$; paired $t$ test) $(B)$. 
cortex treated with HSV-mCREB in animals that were monocularly deprived and then allowed binocular vision, a procedure that promotes recovery of responses to the deprived eye while preserving responses to the experienced eye. In these animals, recovery of cortical binocularity was indistinguishable from that present in untreated regions. Full recovery occurred despite the fact that 1 week of monocular deprivation induces complete loss of responses to the deprived eye (Issa et al., 1999) and a decrease in the complexity of the deprived thalamocortical arbors (Antonini and Stryker, 1996). Previous studies conducted in cats and monkeys have shown that restoration of binocular vision after a short period of deprivation also leads to recovery of responses to the deprived eye (Wiesel and Hubel, 1965; Olson and Freeman, 1978), but recovery of cortical binocularity was less extensive than in ferrets. The finding that ferrets can recover a normal pattern of binocularity after 1 week of monocular deprivation (Liao et al., 2001b) placed us in a unique position to investigate the mechanisms underlying recovery of cortical binocularity. Use of this animal model has indicated that CREB function is not required for the recovery of responses to the previously deprived eye.

The results reported here indicate that there is a mechanistic dichotomy between loss and recovery of cortical binocularity; CREB function is essential for loss but not recovery of deprived eye responses. An alternative interpretation, however, is that injection of HSV-mCREB may not have produced suppression of CREB function. This is unlikely because the results of our CREbinding assays suggest that the MCREB protein is capable of interfering with endogenous CREB activity. Importantly, we also show that the transcription factor $\mathrm{C} / \mathrm{EBP} \beta$, which is regulated by CREB (Niehof et al., 1997), was downregulated in nuclear extracts from HSV-mCREB-injected cortex relative to HSV-LacZinjected or untreated cortex. These findings indicate that intracortical injection of HSV-mCREB produced strong suppression of CREB function near the area of injection.

\section{Previous studies}

Molecular mediators involved in recovery from the effects of monocular deprivation have been examined in very few studies. Specifically, it has been suggested that loss of responses to the deprived eye (Bear et al., 1990; Roberts et al., 1998) as well as recovery of responses after re-establishment of its visual input are dependent on NMDA receptor activation (Gu et al., 1989). In the latter study, the NMDA receptor antagonist 2-amino-5phosphonovalerate was used during reverse suture and was found to prevent recovery of responses to the previously deprived eye. However, blockade of recovery may have been caused by suppression of visual responses by this pharmacological agent (Miller et al., 1989). The involvement of NMDA receptors in binocular recovery needs to be examined using approaches that preserve visual responses (Roberts et al., 1998). More recently, an interesting study showed that inhibition of proteases blocks loss as well as recovery of responses during reverse suture but does not prevent loss of responses during monocular deprivation (Muller and Griesinger, 1998). In contrast, use of viral-mediated gene transfer in the present study has produced consistent results in the monocular deprivation, reverse deprivation, and binocular vision models of ocular dominance plasticity. Inhibition of CREB function prevented loss of responses to the deprived eye in two models of ocular dominance plasticity, monocular deprivation and reverse deprivation. Furthermore, inhibition of CREB function did not block simultaneous recovery of responses to the deprived eye in reverse deprivation. Recovery was similarly unaffected after restoration of binocular vision. In conclusion, the present studies provide direct evidence that loss and recovery of function in the visual cortex occur through independent pathways.

\section{Transcription factors in ocular dominance plasticity}

Gene activation by CREB has been shown to be important for several experimental models of learning (Frank and Greenberg, 1994; Silva et al., 1998) as well as for long-term synaptic plasticity in the hippocampus (Deisseroth et al., 1996). Recent studies have also implicated CREB in ocular dominance plasticity during monocular deprivation (Pham et al., 1999; Mower et al., 2002). $\mathrm{C} / \mathrm{EBP} \beta$ is a transcription factor regulated by CREB (Niehof et al., 1997; Taubenfeld et al., 2001) and is similarly associated with long-term facilitation and long-term memory formation (Alberini et al., 1994; Yukawa et al., 1998; Taubenfeld et al., 2001). These findings sparked our initial interest in the possibility that CREB and $\mathrm{C} / \mathrm{EBP} \beta$ would be required in ocular dominance plasticity during recovery from the effects of monocular deprivation. Finding a lack of effects of mCREB expression on recovery from monocular deprivation was, therefore, surprising. This was especially true in view of the finding that suppression of CREB was effective in preventing loss of responses in the reverse deprivation model. Our results have suggested that $\mathrm{C} / \mathrm{EBP} \beta$ also may not be involved in binocular recovery because HSV-mCREB treatment not only suppressed CREB function but also decreased the expression of $\mathrm{C} / \mathrm{EBP} \beta$ in visual cortex. This finding also raises the interesting possibility that $\mathrm{C} / \mathrm{EBP} \beta$ has an important role in loss of visual responses to the deprived eye. Future tests of this hypothesis as well as the role of CREB function in regulating $\mathrm{C} / \mathrm{EBP} \beta$ expression in the visual cortex should help elucidate what molecular events downstream of CREB activation are required in ocular dominance plasticity during monocular deprivation.

\section{Mechanisms mediating recovery of responses to the deprived eye}

These results raise the issue of what CREB-independent processes might mediate binocular recovery after monocular deprivation. Some possibilities are that local protein synthesis at the synapse is sufficient for recovery of synapses (Stewart et al., 1996; Huber et al., 2000) or that other transcription factors (Brivanlou and Darnell, 2002) regulate recovery. The question of whether recovery requires protein synthesis could be addressed through the use of protein synthesis inhibitors, which have been used successfully to block loss of function (Taha and Stryker, 2002). Another possibility that should be considered is that some deprived eye afferents retain their proximity to postsynaptic contacts, retaining subthreshold inputs on visual cortical neurons during the first days of monocular deprivation (Blakemore et al., 1982). These subthreshold inputs may contact physiologically silent synapses (Isaac et al., 1995; Liao et al., 1995; Liao et al., 2001a), leading to their reactivation after eye opening. Reactivation of silent synapses is a process that can occur rapidly and requires activation of NMDA receptors (Isaac et al., 1995). Finally, it is conceivable that deprived eye afferents make use of molecular cues to re-establish connections with target neurons during binocular recovery. This proposal is reminiscent of recent suggestions that molecular cues may guide formation of ocular dominance modules in the visual cortex (Crowley and Katz, 1999) and eye-specific layers in the lateral geniculate nucleus (Cook et al., 1999). It is important to note, however, that CREB activity may be required for binocular recovery after more prolonged 
durations of deprivation, when expansion of the experienced eye afferents occurs (Antonini and Stryker, 1996). In this case, CREB-dependent loss of these overgrown connections may be necessary to make room for recovering afferents to regain their share of postsynaptic space.

The results presented here have important implications for studies of recovery from monocular deprivation and amblyopia. Many molecules have been implicated in ocular dominance plasticity, but usually in the context of loss of function during monocular deprivation. It is appealing to hypothesize that simple stimulation of pathways associated with these molecules could allow recovery of a deprived eye, even when the critical period has passed. This approach may yield suboptimal results, however, considering the potential mechanistic dichotomy between loss and recovery of function. Therefore, the identity of molecules that may mediate recovery is a topic that demands increased attention.

\section{REFERENCES}

Alberini CM, Ghirardi M, Metz R, Kandel ER (1994) C/EBP is an immediate-early gene required for the consolidation of long-term facilitation in Aplysia. Cell 76:1099-1114.

Antonini A, Stryker MP (1996) Plasticity of geniculocortical afferents following brief or prolonged monocular occlusion in the cat. J Comp Neurol 369:64-82.

Bear MF, Kleinschmidt A, Gu QA, Singer W (1990) Disruption of experience-dependent synaptic modifications in striate cortex by infusion of an NMDA receptor antagonist. J Neurosci 10:909-925.

Beaver CJ, Ji Q, Fischer QS, Daw NW (2001) Cyclic AMP-dependent protein kinase mediates ocular dominance shifts in cat visual cortex. Nat Neurosci 4:159-163.

Birnbaum MH, Koslowe K, Sanet R (1977) Success in ambylopia therapy as a function of age: a literature survey. Am J Optom Physiol Opt 54:269-275.

Blakemore C, Hawken MJ, Mark RF (1982) Brief monocular deprivation leaves subthreshold synaptic input on neurones of the cat's visual cortex. J Physiol (Lond) 327:489-505.

Brivanlou AH, Darnell Jr JE (2002) Signal transduction and the control of gene expression. Science 295:813-818.

Carlezon Jr WA, Thome J, Olson VG, Lane-Ladd SB, Brodkin ES, Hiroi N, Duman RS, Neve RL, Nestler EJ (1998) Regulation of cocaine reward by CREB. Science 282:2272-2275.

Cook PM, Prusky G, Ramoa AS (1999) The role of spontaneous retinal activity before eye opening in the maturation of form and function in the retinogeniculate pathway of the ferret. Vis Neurosci 16:491-501.

Crowley JC, Katz LC (1999) Development of ocular dominance columns in the absence of retinal input. Nat Neurosci 2:1125-1130.

Daw NW (1998) Critical periods and amblyopia. Arch Ophthalmol 116:502-505.

Deisseroth K, Bito H, Tsien RW (1996) Signaling from synapse to nucleus: postsynaptic CREB phosphorylation during multiple forms of hippocampal synaptic plasticity. Neuron 16:89-101.

Finkbeiner S, Tavazoie SF, Maloratsky A, Jacobs KM, Harris KM, Greenberg ME (1997) CREB: a major mediator of neuronal neurotrophin responses. Neuron 19:1031-1047.

Frank DA, Greenberg ME (1994) CREB: a mediator of long-term memory from mollusks to mammals. Cell 79:5-8.

Galuske RA, Kim DS, Castren E, Singer W (2000) Differential effects of neurotrophins on ocular dominance plasticity in developing and adult cat visual cortex. Eur J Neurosci 12:3315-3330.

Gillespie DC, Crair MC, Stryker MP (2000) Neurotrophin-4/5 alters responses and blocks the effect of monocular deprivation in cat visual cortex during the critical period. J Neurosci 20:9174-9186.

Gonzalez GA, Montminy MR (1989) Cyclic AMP stimulates somatostatin gene transcription by phosphorylation of CREB at serine 133 . Cell 59:675-680.

Gu QA, Bear MF, Singer W (1989) Blockade of NMDA-receptors pre- vents ocularity changes in kitten visual cortex after reversed monocular deprivation. Brain Res Dev Brain Res 47:281-288.

Huber KM, Kayser MS, Bear MF (2000) Role for rapid dendritic protein synthesis in hippocampal mGLUR-dependent long-term depression. Science 288:1254-1256.

Isaac JT, Nicoll RA, Malenka RC (1995) Evidence for silent synapses: implications for the expression of LTP. Neuron 15:427-434.

Issa NP, Trachtenberg JT, Chapman B, Zahs KR, Stryker MP (1999) The critical period for ocular dominance plasticity in the ferret's visual cortex. J Neurosci 19:6965-6978.

Levick WR (1972) Another tungsten microelectrode. Med Biol Eng 10:510-515.

Liao D, Hessler NA, Malinow R (1995) Activation of postsynaptically silent synapses during pairing-induced LTP in CA1 region of hippocampal slice. Nature 375:400-404.

Liao D, Scannevin RH, Huganir R (2001a) Activation of silent synapses by rapid activity-dependent synaptic recruitment of AMPA receptors. J Neurosci 21:6008-6017.

Liao DS, Mower AF, Medina AE, Neve RL, Ramoa AS (2001b) Cortical recovery from monocular deprivation in ferrets. Soc Neurosci Abstr 31:244.

Maffei L, Berardi N, Domenici L, Parisi V, Pizzorusso T (1992) Nerve growth factor (NGF) prevents the shift in ocular dominance distribution of visual cortical neurons in monocularly deprived rats. J Neurosci 12:4651-4662.

Miller KD, Chapman B, Stryker MP (1989) Visual responses in adult cat visual cortex depend on $N$-methyl-D-aspartate receptors. Proc Natl Acad Sci USA 86:5183-5187.

Mower AF, Liao DS, Nestler EJ, Neve RL, Ramoa AS (2002) cAMP/ $\mathrm{Ca}^{2+}$ response element-binding protein function is essential for ocular dominance plasticity. J Neurosci 22:2237-2245.

Muller CM, Griesinger CB (1998) Tissue plasminogen activator mediates reverse occlusion plasticity in visual cortex. Nat Neurosci 1:47-53.

Niehof M, Manns MP, Trautwein C (1997) CREB controls LAP/C/EBP beta transcription. Mol Cell Biol 17:3600-3613.

Obata S, Obata J, Das A, Gilbert CD (1999) Molecular correlates of topographic reorganization in primary visual cortex following retinal lesions. Cereb Cortex 9:238-248.

Olson CR, Freeman RD (1978) Monocular deprivation and recovery during sensitive period in kittens. J Neurophysiol 41:65-74.

Pham TA, Impey S, Storm DR, Stryker MP (1999) CRE-mediated gene transcription in neocortical neuronal plasticity during the developmental critical period. Neuron 22:63-72.

Prasad SS, Kojic LZ, Li P, Mitchell DE, Hachisuka A, Sawada J, Gu Q, Cynader MS (2002) Gene expression patterns during enhanced periods of visual cortical plasticity. Neuroscience 111:35-45.

Rauschecker JP, Egert U, Kossel A (1990) Effects of NMDA antagonists on developmental plasticity in kitten visual cortex. Int J Dev Neurosci 8:425-435.

Roberts EB, Meredith MA, Ramoa AS (1998) Suppression of NMDA receptor function using antisense DNA block ocular dominance plasticity while preserving visual responses. J Neurophysiol 80:1021-1032.

Schreiber E, Matthias P, Muller MM, Schaffner W (1989) Rapid detection of octomer binding proteins with "mini-extract", prepared from a small number of cells. Nucleic Acid Res 17:6419.

Silva AJ, Kogan JH, Frankland PW, Kida S (1998) CREB and memory. Annu Rev Neurosci 21:127-148.

Stewart O, Falk OM, Torre ER (1996) Ultrastructural basis for gene expression at the synapse: synapse-associated polyribosome complexes. J Neurocytol 25:717-734.

Taha S, Stryker MP (2002) Rapid ocular dominance plasticity requires cortical but not geniculate protein synthesis. Neuron 34:425-436.

Taubenfeld SM, Wiig KA, Monti B, Dolan B, Pollonini G, Alberini CM (2001) Fornix-dependent induction of hippocampal CCAAT enhancer-binding protein $\beta$ and $\delta$ co-localizes with phosphorylated cAMP response element-binding protein and accompanies long-term memory consolidation. J Neurosci 21:84-91.

Wiesel TN, Hubel DH (1965) Comparison of the effects of unilateral and bilateral eye closure on cortical unit responses in kittens. J Neurophysiol 28:1029-1040.

Yukawa K, Tanaka T, Tsuji S, Akira S (1998) Expressions of CCAAT/ Enhancer-binding proteins beta and delta and their activities are intensified by cAMP signaling as well as $\mathrm{Ca}^{2+} /$ calmodulin kinases activation in hippocampal neurons. J Biol Chem 273:31345-31351. 